\title{
A study of Life Internal Rate of Return
}

\author{
SORRAWEE ROENGANAN ${ }^{1}$, MASNITA MISRAN ${ }^{2}$, NATTAKORN PHEWCHEAN*1,3 \\ ${ }^{1}$ Department of Mathematics, Faculty of Science, Mahidol University \\ Rama 6 rd., Bangkok 10400, THAILAND \\ ${ }^{2}$ School of Quantitative Sciences, UUM College of Arts and Sciences, Universiti Utara Malaysia, \\ 06010 UUM Sintok, Kedah Darul Aman, MALAYSIA. \\ ${ }^{3}$ Centre of Excellence in Mathematics, PERDO, THAILAND \\ *corresponding author: nattakorn.phe@mahidol.ac.th https://mathematics.sc.mahidol.ac.th
}

\begin{abstract}
Life insurance, not included as a part of the legal obligation in some countries, is one of the investment approaches that might not stand high in the public favor for some people since this is a type of investments that the investor cannot know beforehand the exact return, and the returns completely depend on uncertainty of the policy specification in some circumstances. Similar to the other kinds of investment, investors in life insurance products have been seeking a tool for investment evaluation. However, currently there are no accurate tools that can provide the value of the investment in a life insurance product sensitive to the uncertainty. Internal rate of return is the basic tool that buyers or bankers may apply in order to find the rate of return of this type of investment. The investment decision tool is one of the most important keys that investors have utilized upon making their decisions on investments. Therefore, in this research, we propose a new mathematical model with applications for investment decision, being an extension of the internal rate of return by taking into account the life probability, considering different types of life insurance policies, and other factors specified on life insurance investments such as the premium, the death benefit, the maturity value, the sum insured, the lapse rate, the surrender value, the annuity certain, and the lapse rate with different genders and ages. This newly proposed model is named as the "Life Internal Rate of Return" or Life-IRR model. By using the sample data for both males and females aged 30 years old with expected benefit of 100,000 baht for different types of life insurance policies which are endowment plan, whole life plan and retirement plan, the results show that, for males, the highest life rate of returns is that obtained from the retirement plan (3.633692\%), and the lowest life internal rates of returns is that obtained from the endowment plan $(2.384443 \%)$, while the whole life plan offers moderate life rate of returns of $2.427941 \%$. For females, the highest life rate of returns is that obtained from the retirement plan $(3.335189 \%)$, and the lowest life internal rates of returns is that obtained from the whole life plan $(2.104658 \%)$, while the endowment plan offers moderate life rate of returns of $2.308062 \%$. The sensitivity analyses of the life internal rates of return perform the natural characteristics of life insurance.
\end{abstract}

Key-Words: - Life internal rate of return, Internal rate of return, Net present value, Life insurance.

Received: November 8, 2021. Revised: March 11, 2021. Accepted: March 29, 2021. Published: April 15, 2021.

\section{Introduction}

Nowadays, investment has been popular with people who are looking for the benefit that provides the highest return. The higher the return of the investment, the more interest it will receive. Generally, people prefer investing in properties, funds, and stocks because of its obvious return, unlike investing in life insurance. Especially in developing countries, when life insurance is not mandatory for anyone, life insurance is one of the least popular investments for investors. For example, as it can be seen from the statistical data of Growth \& Credibility 2016-2020 magazine provided by the Office of Insurance Commission of Thailand, only $37 \%$ of the Thai people purchases life insurance products. This number is much smaller than those in Malaysia, Japan, Singapore, and South Korea [1].
Many Thai people would like to purchase life insurance products while requiring knowledge of accurate return that they will receive.

There are many types of life insurance policies in Thailand. The most common types of life insurance policies are whole life, endowment, term life, and retirement insurance [2], each of which has different elements; as a result, making the decision to invest in each type of life insurance is more difficult. But if only comparing the returns, the easiest way to make investment decision is to find the net benefit by calculating the difference between the money paid and the money received. However, the use of this approach does not taken into account the time value of money which is not really applicable in the world of finance [3]. 
Currently, there are two methods that are widely used to estimate the return of investment in making a decision to invest, which are the net present value (NPV) method and the internal rate of return method (IRR) method [4]. Until now, many researchers have studied both methods on the investment [5]. In 1963 , Turvey [6] explained about the net present value and the internal rate of return in the theory of the $3 \mathrm{rd}$ best. In 2010, Magni [7] stated that the internal rate of return was often used by investment managers in making a decision on investment. However, the internal rate of return has serious flaws, one of which is that some internal rates of return are not applicable to many cases or situations, when compared to the net present value (NPV) which is a more favorable method to evaluate the returns of investments. Thus, Magni offered in [7] a tool of measurement for investment decision that was named as the "Average Internal Rate of Return", the result of which is consistent with the net present value.

In 2011, Juhász [8] studied both the net present value method and the internal rate of return method. The net present value showed how an investment accumulated wealth growth during that period by using the minimum expected rate of return, but it was not explained the true profit of those investors and the internal rate of return method showed the real rate return that the investor received from long capital investment. In 2013, Romele [9] commented that the internal rate of return showed the efficiency of the investment as the return of individuals. A relevant studies of risk management can be found in [10-11]. In 1993, Feldblum [12] explained that, in every investment, the time value of money is one of the most essential part for financial analysis. $\mathrm{He}$ considered the framework of the internal rate of return model and applied it to the price of insurance policy. In life insurance, many authors studied and carried out extensive research about internal rate of return applied with each type of life insurance policies [13-14]. In 1974, Kensicki [15] analyzed life insurance policies as cash and cash flow opportunities, and compared the values of the insurance in terms of return rate and the net present value of the insured. He commented that both the internal rate of return and the net present value formula showed the time value of money and the duration of the benefit.

The elements of the life insurance policy have been studied as well. In 1978, Belth [16] stated that many life insurance companies used a three-factor contribution method to determine dividends. In 1982, Smith [17] studied the option package which has more aspects of the life insurance policy (for example, renewal guarantee, surrender cash value, option to borrow, and so on) than in the conventional savings-and-protection point of view. $\mathrm{He}$ also discussed in [16] the options for cost disclosure and product development.

In 2018, however, Milhaud and Dutang [18], focused on the surrender behaviors and the model of a lifetime by using the survival regression models. He aimed to provide an accurate prediction for the timing of the lapse of a policyholder. Having said all of this, it can be seen that the internal rate is very important investment decision tool, and investors of life insurance can also use the internal rate of return method.

In 2016, Dash [19] created the mathematical model of the rate of return for life insurance from many different types of life insurance policies in India. He utilized the internal rate of return (IRR) to describe the benefit rate which depended on premium, death benefit, and maturity value including life probability.

Therefore, the purpose of this paper is to create an investment tool with a mathematical model called the "Life Internal Rate of Return" model that contains various elements of life insurance taking into account the life probabilities in connection to, for example, premium, death benefit, maturity value, annuity certain, dividend, lapse rate, and surrender value. The applications of the model are numerically presented to provide an illustration of the proposed investment tool of life insurance.

\section{Sample Data}

In this research, we randomly select sample data for both males and females aged 30 years old for different types of life insurance policies. The data of life insurance policies are endowment plan, whole life plan and retirement plan. The mortality table of Thai population in 2017 is applied for probability calculation [20]. It is noted that in each policy plan, the benefit is expected the same number of 100,000 baht, under the same age.

\subsection{Endowment insurance}

For an endowment policy, the benefit of this plan is the combination of both insurance coverage and saving plan that insured will receive a lump sum on death or after the end date of the policy or maturity date. This plan has a short time frame; therefore, the return may be less than the other insurance types.

The investor may invest in this product by purchasing from a Life Insurance Company and it may be evaluated as a regular lifesaving plan with life assurance of the death benefit protection. It is given 
a data of males and females aged 30 years old paying the annual premium of 9,500 baht until the age of 40 years, who receive annual dividend since $2^{\text {nd }}$ policy year until maturity date (the end of the 15th policy year), and receive the maturity value of 100,000 baht from sum assured of 100,000 baht. If the insured dies, the beneficiary will get death benefit of 100,000 baht. Moreover, if the insured ceases to pay the premium, the insured will get the surrender value of the policy of each policy year that shown in Table 1 .

Table 1 The surrender value of endowment plan

\begin{tabular}{|c|c|c|}
\hline $\begin{array}{l}\text { Policy } \\
\text { Year }\end{array}$ & $\begin{array}{c}\text { Dividend } \\
\text { (Baht) }\end{array}$ & $\begin{array}{c}\text { Surrender Value } \\
\text { (Baht) }\end{array}$ \\
\hline 1 & - & - \\
\hline 2 & 190 & 5,000 \\
\hline 3 & 240 & 11,000 \\
\hline 4 & 290 & 18,000 \\
\hline 5 & 340 & 26,000 \\
\hline 6 & 390 & 35,000 \\
\hline 7 & 440 & 45,000 \\
\hline 8 & 190 & 55,000 \\
\hline 9 & 540 & 65,000 \\
\hline 10 & 590 & 75,000 \\
\hline 11 & 600 & 80,000 \\
\hline 12 & 610 & 85,000 \\
\hline 13 & 620 & 90,000 \\
\hline 14 & 630 & 95,000 \\
\hline 15 & 640 & 100,000 \\
\hline
\end{tabular}

\subsection{Whole life insurance}

For a whole life policy, males and females aged 30 years old purchase a whole life product with the sum assured of 100,000 baht for a payment of an annual premium of 3,000 baht for 20 years, death benefit of 100,000 baht, maturity benefit at the maturity date, when the insured reaches the age of 90 years, of $100,000 \mathrm{baht}$, and the surrender value given in Table 2. It is noted that the whole life insurance has an advantage of inheritance that will be given to a beneficiary after the death of the insured.

\subsection{Retirement insurance}

The retirement insurance is a plan that provides a death benefit if the insured dies before a stated retirement age or a life income if the insured survives to that retirement age. For the premium of the sample data, we set the accumulated premium to be less than the sum assured which refers to a feature of retirement insurance contract. While the surrender value in the early period, we set a low surrender value in each period due to the risk of termination of the contract and the surrender value will increase time by time approaching the sum insured of the contract.

For a retirement policy, it is given the sum assured of 100,000 baht for a male or a female 30 years old. $\mathrm{He} / \mathrm{she}$ pays the premium of 2,500 baht per year until he/she reaches the age of 60 years. It is assumed that the retirement age is 60 . Also, he/she will receive 100,000 baht at the day of retirement. However, if he/she dies before the age of 60 , the death benefit of this policy of 100,000 baht will be paid to the beneficiary. The surrender value follows Table 3 .

Table 2 The surrender value of whole life plan

\begin{tabular}{|c|c|c|c|}
\hline $\begin{array}{l}\text { Policy } \\
\text { Year }\end{array}$ & $\begin{array}{c}\text { Surrender } \\
\text { Value (Baht) }\end{array}$ & $\begin{array}{c}\text { Policy } \\
\text { Year }\end{array}$ & $\begin{array}{c}\text { Surrender } \\
\text { Value (Baht) }\end{array}$ \\
\hline 1 & - & 31 & 46,000 \\
\hline 2 & 500 & 32 & 47,500 \\
\hline 3 & 1,500 & 33 & 49,000 \\
\hline 4 & 2,500 & 34 & 50,000 \\
\hline 5 & 3,500 & 35 & 51,000 \\
\hline 6 & 4,500 & 36 & 52,000 \\
\hline 7 & 6,000 & 37 & 53,000 \\
\hline 8 & 7,500 & 38 & 54,000 \\
\hline 9 & 9,000 & 39 & 55,000 \\
\hline 10 & 10,500 & 40 & 56,000 \\
\hline 11 & 12,500 & 41 & 57,500 \\
\hline 12 & 14,500 & 42 & 59,000 \\
\hline 13 & 16,500 & 43 & 60,500 \\
\hline 14 & 18,500 & 44 & 62,000 \\
\hline 15 & 21,000 & 45 & 63,500 \\
\hline 16 & 23,500 & 46 & 65,500 \\
\hline 17 & 26,000 & 47 & 67,500 \\
\hline 18 & 27,500 & 48 & 69,500 \\
\hline 19 & 30,500 & 49 & 71,500 \\
\hline 20 & 33,500 & 50 & 73,500 \\
\hline 21 & 34,500 & 51 & 75,500 \\
\hline 22 & 35,500 & 52 & 78,000 \\
\hline 23 & 36,500 & 53 & 80,500 \\
\hline 24 & 37,500 & 54 & 83,000 \\
\hline 25 & 38,500 & 55 & 85,500 \\
\hline 26 & 39,500 & 56 & 88,000 \\
\hline 27 & 40,500 & 57 & 91,000 \\
\hline 28 & 41,500 & 58 & 94,000 \\
\hline 29 & 43,000 & 59 & 97,000 \\
\hline 30 & 44,500 & 60 & 100,000 \\
\hline
\end{tabular}


Table 3 The surrender value of retirement plan

\begin{tabular}{|c|c|c|c|}
\hline $\begin{array}{c}\text { Policy } \\
\text { Year }\end{array}$ & $\begin{array}{c}\text { Surrender } \\
\text { Value of } \\
\text { Policy Year } \\
\text { (Baht) }\end{array}$ & $\begin{array}{c}\text { Policy } \\
\text { Year }\end{array}$ & $\begin{array}{c}\text { Surrender } \\
\text { Value of } \\
\text { Policy Year } \\
\text { (Baht) }\end{array}$ \\
\hline 1 & - & 16 & 32,500 \\
\hline 2 & 1,000 & 17 & 36,000 \\
\hline 3 & 3,000 & 18 & 39,500 \\
\hline 4 & 5,000 & 19 & 43,000 \\
\hline 5 & 7,000 & 20 & 46,500 \\
\hline 6 & 9,000 & 21 & 50,000 \\
\hline 7 & 11,000 & 22 & 54,000 \\
\hline 8 & 13,000 & 23 & 58,000 \\
\hline 9 & 15,000 & 24 & 62,000 \\
\hline 10 & 17,000 & 25 & 66,000 \\
\hline 11 & 19,500 & 26 & 70,000 \\
\hline 12 & 22,000 & 27 & 75,000 \\
\hline 13 & 24,500 & 28 & 80,000 \\
\hline 14 & 27,000 & 29 & 95,000 \\
\hline 15 & 29,500 & 30 & 100,000 \\
\hline
\end{tabular}

Moreover, in the retirement plan, the customers can choose to receive maturity benefits in installments. From the above example of retirement plan for a 30-year-old person, we will evaluate the life internal rate of return of this situation in the case that he/she chooses to receive installments of 7,000 baht until the age of 80 .

When people need to purchase a life insurance product, the most important thing for valuation of product and making a decision on the investment is to choose the product that satisfies demand and requirement with the highest benefit. Many factors, such as age, gender, annual premium, payment period, coverage period, and sum assured are taken into account the calculation of life internal rate of return. All of the above data are the sample data to show the application of life internal rate of return model.

\section{Mathematical Model}

The basic internal rate or return model can be expressed as follows:

$$
\mathrm{NPV}=-\sum_{j=0}^{m} \frac{M O_{j}}{(1+r)^{j}}+\sum_{j=1}^{m} \frac{M I j}{(1+r)^{j}}
$$

where $M O_{0}$ is the initial money paid out at the start of the investment,
$M O_{j}$ is the money paid out at year $j$, during year 1 to year $m$,

$m$ is the end date of investment period,

$M I_{j}$ is the money received in at year during year 1 to year $m$ with internal rate of return $r$. The internal rate of return is a discount rate $r$ that fixed the net present value (NPV) equal to zero.

For decades, the mathematical model for finding the internal rate of return of life insurance has been applied as

$$
\mathrm{NPV}=-\sum_{j=0}^{m-1} \frac{P}{(1+r)^{j}}+\frac{M V}{(1+r)^{j}}+\sum_{j=t}^{s} \frac{A C_{j}}{(1+r)^{j}}
$$

where $P$ is the annual premium,

$r$ is the rate of return,

$m$ is the maturity date,

$M V$ is the maturity value,

$A C_{j}$ is the annuity certain between year $t$ to year $s$

Equation (2) considers only three elements of the life insurance policy, which are annual premium, maturity benefit, and annuity certain. Therefore, in this study, we proposed a mathematical model that includes all elements that strongly affect to the rate of return of life insurance policy and significantly have an influence to the investment decisions.

Therefore, the proposed "Life Internal Rate of Return" model is a general form of the basic internal rate of return (IRR) of life insurance, a brief description of which is given in the Appendix, taking into account the mortality rate, the death benefit, the dividend, and the surrender value. This extension of the model is intended to provide accurate and suitable results under various conditions of life insurance. The net present value of the investment for a life insurance product can be evaluated by the following mathematical model:

$$
\begin{gathered}
\mathrm{NPV}=-\sum_{j=0}^{n-1} \frac{P}{(1+r)^{j}} p_{j}^{(k)}+\frac{M V}{(1+r)^{m}} p_{m}^{(k)} \\
+\sum_{j=1}^{m} \frac{D B_{j}}{(1+r)^{j}} q_{j}^{(k)}+\sum_{j=u}^{m} \frac{D_{j}}{(1+r)^{j}} p_{j}^{(k)} \\
+\sum_{j=t}^{S} \frac{A C_{j}}{(1+r)^{j}} p_{j}^{(k)}+\sum_{j=1}^{m} \frac{S_{j}}{(1+r)^{j}} L_{j}
\end{gathered}
$$

where $P$ is the premium per annum,

$k$ is the age of insured in integral year,

$r$ is the rate of return, 
$n \quad$ is the last period of payment,

$m$ is the maturity date,

$M V$ is the maturity benefit,

$D B_{j}$ is the death benefit of $j^{\text {th }}$ year (Baht),

$D_{j}$ is the annual dividend at the end of

policy year $j$ that pays between $u^{\text {th }}$

year to maturity date,

$A C_{j}$ is the annuity certain or guaranteed

payment at the end of policy year $j$ that

pays between year $t$ and year $s$,

$S_{j}$ is the surrender value of the policy at the end of policy year (Baht), and

$L_{j}$ is the lapse rate.

Here, $p_{j}^{(k)}$ is the probability that a person aged $k$ will survive $j$ years and can be calculated by

$$
p_{j}^{(k)}=\left(p_{k}\right)\left(p_{k+1}\right)\left(p_{k+2}\right) \cdots\left(p_{k+j-1}\right)=\prod_{i=0}^{j-1} p_{k+i}
$$

where $p_{k}$ is the survival probability.

$q_{j}^{(k)}$ is the probability that a person aged $k$ will die in $j^{\text {th }}$ years and can be calculated by

$$
\begin{aligned}
q_{j}^{(k)} & =\left(p_{k}\right)\left(p_{k+1}\right)\left(p_{k+2}\right) \cdots\left(p_{k+j-2}\right)\left(1-p_{k+j-1}\right) \\
& =\left(\prod_{i=0}^{j-1} p_{k+i}\right)\left(1-p_{k+j-1}\right)
\end{aligned}
$$

Equation (3) shows the internal rate of return that is composed of elements of life insurance and can be separated into two transactions: the first part is the money paid out as the negative term and the second part is the money paid out as the positive term.

The first part, which has negative value and depends on the probability of living of the investor, has only one term that is the premium term, since the policyholder pays the premium out as the investment for an exchange of benefit returns. This term can be expressed as the summation of actuarial present values of all premiums. Mathematically, this term,

$$
-\sum_{j=0}^{n-1} \frac{P}{(1+r)^{j}} p_{j}^{(k)},
$$

depends on the premium that the insured survives each year, starting the beginning between the $1^{\text {st }}$ year to the $n$ year, and invested at the rate of return . It is noted that premium payment of each person depends upon the type of life insurance policy.

The second part of the model in (3) represents the return of life insurance investment to the insured when the investor dies or survives. The first term is the maturity value term,

$$
\frac{M V}{(1+r)^{m}} p_{m}^{(k)}
$$

that gives the actuarial present value of one-time payment of the return when the policy owner survives until the maturity date ( $m^{\text {th }}$ year). Next, the term of the death benefit depending on the probability of the death of investor,

$$
\sum_{j=1}^{m} \frac{D B}{(1+r)^{j}} q_{j}^{(k)}
$$

describes the actuarial present value of the benefit that the beneficiary will receive as the payout when the policy owner dies. The death benefit payment may be varied depending on the details of the policy of each company. Another component of the model, we propose that the actuarial present value of dividend term follows the formula below:

$$
\sum_{j=u}^{m} \frac{D_{j}}{(1+r)^{j}} p_{j}^{(k)}
$$

The dividend is an annual payment given by the insurer to the insured between year $u$ and year $m$ (most policies starting from the $2^{\text {nd }}$ year). The dividend may be changed each year based on the annual turnover of the companies that take investment from the premium of the insured; consequently, it is not obligated to be paid every year. In the next term in (3), we account for actuarial present value of all payments that are the payout of investment return for each year between $t^{\text {th }}$ and $s^{\text {th }}$ years. Mostly, this term may be stated in the pension life insurance. It may be called the "annuity certain" and can be calculated by

$$
\sum_{j=t}^{s} \frac{A C_{j}}{(1+r)^{j}} p_{j}^{(k)} .
$$

Lastly, the actuarial present value is a summation of all surrender values which are subject to the lapse rates with the cash surrender values in corresponding 
periods of time. As a result, the actuarial probabilities that correspond to the surrender values are lapse rates instead of the probabilities of living or dying as it is shown in the previous terms. This can be mathematically represented as

$$
\sum_{j=1}^{m} \frac{S_{j}}{(1+r)^{j}} L_{j} .
$$

It is noted that the lapse rate of each policy is not available publicly for all policies. Hence, we assume the lapse rate as follows:

$$
L_{j}=\left\{\begin{array}{ccc}
0 & ; & j=1 \\
0.03 & ; & 1<j \leq 4 \\
0.02 & ; & 4<j \leq n \\
0.01 & ; & n<j \leq m
\end{array}\right.
$$

where $j$ is the policy year. In the first year, every customer has paid the premium to activate the policy so that $L_{1}=0$. During year 1 to year 4 , we assume $3 \%$ lapse rate, the highest rate, since some policyholders may lack of ability to pay the premium or may make a decision to stop the premium payment easily since during the early period the investor may just pay the premiums for only a few times. Conversely, premium payments for the remaining years have lower probabilities of lapse rate. It is less likely that the policyholders will cancel premium payments during this period. Hence, we assume that the lapse rate from year 5 to the last year of premium payment, year $n$, is $2 \%$. Finally, after the payment period, there are still few customers who wish to cancel and receive their policy benefits before the maturity year $m$, and therefore, we set the lapse rate for this period to be $1 \%$ which is lower, having a less percent chance of occurrence when compared to the other previous periods.

Finally, we evaluate the life internal rate of return by equating the net present value (NPV) to zero, which can be expressed as follows:

$$
\begin{aligned}
0= & -\sum_{j=0}^{n-1} \frac{P}{(1+r)^{j}} p_{j}^{(k)}+\frac{M V}{(1+r)^{m}} p_{m}^{(k)} \\
& +\sum_{j=1}^{m} \frac{D B}{(1+r)^{j}} q_{j}^{(k)}+\sum_{j=u}^{m} \frac{D_{j}}{(1+r)^{j}} p_{j}^{(k)} \\
& +\sum_{j=t}^{S} \frac{A C C_{j}}{(1+r)^{j}} p_{j}^{(k)}+\sum_{j=1}^{m} \frac{S_{j}}{(1+r)^{j}} L_{j}
\end{aligned}
$$

Next, we will use the data in section 2 to calculate the life internal rate of return of each type of life insurance policies.

\section{Evaluation Results}

The life internal rate of return is represented by $r$ and can be calculated by using equation (6) in each type of life insurance investments. The following calculations are numerical samples of endowment plan, whole life plan and retirement plan calculations, the data for which are provided in section 2 . Applications of the life internal rate of return model utilized as a tool for investment decisions are shown as in what follows.

\subsection{Endowment insurance}

We detail the data of endowment plan in Table 4 with the maturity value of 100,000 baht.

Table 4 Summary benefit and coverage of endowment plan

\begin{tabular}{|c|c|c|c|c|}
\hline $\begin{array}{c}\text { Yr } \\
(j)\end{array}$ & $\begin{array}{c}\text { Annual } \\
\text { Premium } \\
\left(P_{j}\right)\end{array}$ & $\begin{array}{c}\text { Death } \\
\text { Benefit } \\
\left(D B_{j}\right)\end{array}$ & $\begin{array}{c}\text { Surrende } \\
\text { r Value } \\
\left(S_{j}\right)\end{array}$ & $\begin{array}{c}\text { Annual } \\
\text { Dividend } \\
\left(D_{j}\right)\end{array}$ \\
\hline 1 & 9,500 & 100,000 & - & - \\
\hline 2 & 9,500 & 100,000 & 5,000 & 190 \\
\hline 3 & 9,500 & 100,000 & 11,000 & 240 \\
\hline 4 & 9,500 & 100,000 & 18,000 & 290 \\
\hline 5 & 9,500 & 100,000 & 26,000 & 340 \\
\hline 6 & 9,500 & 100,000 & 35,000 & 390 \\
\hline 7 & 9,500 & 100,000 & 45,000 & 440 \\
\hline 8 & 9,500 & 100,000 & 55,000 & 490 \\
\hline 9 & 9,500 & 100,000 & 65,000 & 540 \\
\hline 10 & 9,500 & 100,000 & 78,000 & 590 \\
\hline 11 & - & 100,000 & 80,000 & 600 \\
\hline 12 & - & 100,000 & 85,000 & 610 \\
\hline 13 & - & 100,000 & 90,000 & 620 \\
\hline 14 & - & 100,000 & 95,000 & 630 \\
\hline 15 & - & 100,000 & 100,000 & 640 \\
\hline
\end{tabular}

In this plan, our calculation gives the life internal rate of return to be approximately $2.308062 \%$ for a female aged 30 and $2.384443 \%$ for a male aged 30 .

\subsection{Whole life insurance}

The information in Tables 5 and 6 is the details of an example of the payment of the whole life policy for both males and females aged 30, where the maturity benefit at the maturity date when the insured reaches the age of 90 is 100,000 baht. It is noted that in this 
Table 5 Summary benefit and coverage of whole life plan (years 1-30)

\begin{tabular}{|c|c|c|c|}
\hline $\begin{array}{l}\text { Policy } \\
\text { Year } \\
(j)\end{array}$ & $\begin{array}{c}\text { Annual } \\
\text { Premium } \\
\left(P_{j}\right)\end{array}$ & $\begin{array}{l}\text { Death } \\
\text { Benefit } \\
\left(D B_{j}\right)\end{array}$ & $\begin{array}{c}\text { Surrender } \\
\text { Value of } \\
\text { Policy Year } \\
\quad\left(S_{j}\right)\end{array}$ \\
\hline 1 & 3,000 & 100,000 & - \\
\hline 2 & 3,000 & 100,000 & 500 \\
\hline 3 & 3,000 & 100,000 & 1,500 \\
\hline 4 & 3,000 & 100,000 & 2,500 \\
\hline 5 & 3,000 & 100,000 & 3,500 \\
\hline 6 & 3,000 & 100,000 & 4,500 \\
\hline 7 & 3,000 & 100,000 & 6,000 \\
\hline 8 & 3,000 & 100,000 & 7,500 \\
\hline 9 & 3,000 & 100,000 & 9,000 \\
\hline 10 & 3,000 & 100,000 & 10,500 \\
\hline 11 & 3,000 & 100,000 & 12,500 \\
\hline 12 & 3,000 & 100,000 & 14,500 \\
\hline 13 & 3,000 & 100,000 & 16,500 \\
\hline 14 & 3,000 & 100,000 & 18,500 \\
\hline 15 & 3,000 & 100,000 & 21,000 \\
\hline 16 & 3,000 & 100,000 & 23,500 \\
\hline 17 & 3,000 & 100,000 & 26,000 \\
\hline 18 & 3,000 & 100,000 & 27,500 \\
\hline 19 & 3,000 & 100,000 & 30,500 \\
\hline 20 & 3,000 & 100,000 & 33,500 \\
\hline 21 & - & 100,000 & 34,500 \\
\hline 22 & - & 100,000 & 35,500 \\
\hline 23 & - & 100,000 & 36,500 \\
\hline 24 & - & 100,000 & 37,500 \\
\hline 25 & - & 100,000 & 38,500 \\
\hline 26 & - & 100,000 & 39,500 \\
\hline 27 & - & 100,000 & 40,500 \\
\hline 28 & - & 100,000 & 41,500 \\
\hline 29 & - & 100,000 & 43,000 \\
\hline 30 & - & 100,000 & 44,500 \\
\hline
\end{tabular}

type of policy, we randomly choose the premiums to be paid in 20 years with the whole life coverage.

In this case, the life internal rate of return of 30years-old male is $2.427941 \%$ and 30 years-old female is $2.104658 \%$.

\subsection{Retirement insurance}

The data of retirement policy of both genders are shown in Table 7. It is noted that the maturity benefit when an investor reaches to age 60 is 100,000 baht.

From a sample data, randomized to test our model, by choosing lump sum payment, a 30-years-old male, who invests his money in the provided retirement insurance policy, will have the life internal rate of
Table 6 Summary benefit and coverage of whole life plan (years 31-60)

\begin{tabular}{|c|c|c|c|}
\hline $\begin{array}{c}\text { Policy } \\
\text { Year } \\
(j)\end{array}$ & $\begin{array}{c}\text { Annual } \\
\text { Premium } \\
\left(P_{j}\right)\end{array}$ & $\begin{array}{c}\text { Death } \\
\text { Benefit } \\
\left(D B_{j}\right)\end{array}$ & $\begin{array}{c}\text { Surrender } \\
\text { Value of } \\
\text { Policy Year } \\
\left(S_{j}\right)\end{array}$ \\
\hline 31 & - & 100,000 & 46,000 \\
\hline 32 & - & 100,000 & 47,500 \\
\hline 33 & - & 100,000 & 49,000 \\
\hline 34 & - & 100,000 & 50,000 \\
\hline 35 & - & 100,000 & 51,000 \\
\hline 36 & - & 100,000 & 52,000 \\
\hline 37 & - & 100,000 & 53,000 \\
\hline 38 & - & 100,000 & 54,000 \\
\hline 39 & - & 100,000 & 55,000 \\
\hline 40 & - & 100,000 & 56,000 \\
\hline 41 & - & 100,000 & 57,500 \\
\hline 42 & - & 100,000 & 59,000 \\
\hline 43 & - & 100,000 & 60,500 \\
\hline 44 & - & 100,000 & 62,000 \\
\hline 45 & - & 100,000 & 63,500 \\
\hline 46 & - & 100,000 & 65,500 \\
\hline 47 & - & 100,000 & 67,500 \\
\hline 48 & - & 100,000 & 69,500 \\
\hline 49 & - & 100,000 & 71,500 \\
\hline 50 & - & 100,000 & 73,500 \\
\hline 51 & - & 100,000 & 75,500 \\
\hline 52 & - & 100,000 & 78,000 \\
\hline 53 & - & 100,000 & 80,500 \\
\hline 54 & - & 100,000 & 83,000 \\
\hline 55 & - & 100,000 & 85,500 \\
\hline 56 & - & 100,000 & 88,000 \\
\hline 57 & - & 100,000 & 81,000 \\
\hline 58 & - & 100,000 & 94,000 \\
\hline 59 & - & 100,000 & 97,000 \\
\hline 60 & - & 100,000 & 100,000 \\
\hline
\end{tabular}

return of $3.633692 \%$ from his investment, while a 30 years-old female will have the life internal rate of return of $3.335189 \%$.

However, in the case that the investor chooses to receive 7,000 baht installments up to the age of 80 , the life internal rate of returns will be $3.120377 \%$ and $3.138876 \%$ for males and females, respectively.

\subsection{Evaluation summary}

From numerical samplings carried out in the cases of endowment plan, whole life plan and retirement plan calculations, described in 4.1, 4.2 and 4.3, we have the results of investment for an investor, either male or female, under the age of 30 years old. 
Table 7 Summary benefit and coverage of retirement plan (years 1-30)

\begin{tabular}{|c|c|c|c|}
\hline $\begin{array}{c}\text { Policy } \\
\text { Year } \\
(j)\end{array}$ & $\begin{array}{c}\text { Annual } \\
\text { Premium } \\
\left(P_{j}\right)\end{array}$ & $\begin{array}{c}\text { Death } \\
\text { Benefit } \\
\left(D B_{j}\right)\end{array}$ & $\begin{array}{c}\text { Surrender } \\
\text { Value of } \\
\text { Policy Year } \\
\quad\left(S_{j}\right)\end{array}$ \\
\hline 1 & 2,500 & 100,000 & - \\
\hline 2 & 2,500 & 100,000 & 1,000 \\
\hline 3 & 2,500 & 100,000 & 3,000 \\
\hline 4 & 2,500 & 100,000 & 5,000 \\
\hline 5 & 2,500 & 100,000 & 7,000 \\
\hline 6 & 2,500 & 100,000 & 9,000 \\
\hline 7 & 2,500 & 100,000 & 11,000 \\
\hline 8 & 2,500 & 100,000 & 13,000 \\
\hline 9 & 2,500 & 100,000 & 15,000 \\
\hline 10 & 2,500 & 100,000 & 17,000 \\
\hline 11 & 2,500 & 100,000 & 19,500 \\
\hline 12 & 2,500 & 100,000 & 22,000 \\
\hline 13 & 2,500 & 100,000 & 24,500 \\
\hline 14 & 2,500 & 100,000 & 27,000 \\
\hline 15 & 2,500 & 100,000 & 29,500 \\
\hline 16 & 2,500 & 100,000 & 32,500 \\
\hline 17 & 2,500 & 100,000 & 36,000 \\
\hline 18 & 2,500 & 100,000 & 39,500 \\
\hline 19 & 2,500 & 100,000 & 43,000 \\
\hline 20 & 2,500 & 100,000 & 46,500 \\
\hline 21 & 2,500 & 100,000 & 50,000 \\
\hline 22 & 2,500 & 100,000 & 54,000 \\
\hline 23 & 2,500 & 100,000 & 58,000 \\
\hline 24 & 2,500 & 100,000 & 62,000 \\
\hline 25 & 2,500 & 100,000 & 66,000 \\
\hline 26 & 2,500 & 100,000 & 70,000 \\
\hline 27 & 2,500 & 100,000 & 75,000 \\
\hline 28 & 2,500 & 100,000 & 80,000 \\
\hline 29 & 2,500 & 100,000 & 95,000 \\
\hline 30 & 2,500 & 100,000 & 100,000 \\
\hline
\end{tabular}

It can be seen that, by expecting the benefit of 100,000 baht with the different plans of investment, under the same age, for males, the highest life rate of returns is that obtained from the retirement plan $(3.633692 \%)$, and the lowest life internal rates of returns is that obtained from the endowment plan $(2.384443 \%)$, while the whole life plan offers moderate life rate of returns of $2.427941 \%$.

For females, the highest life rate of returns is that obtained from the retirement plan $(3.335189 \%)$, and the lowest life internal rates of returns is that obtained from the whole life plan $(2.104658 \%)$, while the endowment plan offers moderate life rate of returns of $2.308062 \%$.

\section{Sensitivity Analysis}

The sensitivity analysis considers how different values of the independent variables affect the dependent variable under the given assumptions. In this work, based on the assumptions in section 4, we analyse the impact of the change of premium and dividend on the proposed life internal rate of return.

\subsection{Endowment insurance}

For the endowment insurance that has a premium payment period of 10 years and a coverage period of 15 years, we consider several premiums and dividends at different ages of the insured, which are 20,40 , and 60 years old to represent different age categories. The results of the sensitivity of the life internal rate of return on the change of annual premium of male and female are shown in Table 8 , and Table 9, respectively.

Table 8 Sensitivity of life internal rates of return on premium of endowment plan for male.

\begin{tabular}{|c|c|c|c|} 
Aged & 20 & 40 & 60 \\
Premium & & & \\
\hline 7,500 & $4.911712 \%$ & $5.083942 \%$ & $6.505091 \%$ \\
\hline 8,000 & $4.208154 \%$ & $4.362633 \%$ & $5.634056 \%$ \\
\hline 8,500 & $3.551861 \%$ & $3.692646 \%$ & $4.830678 \%$ \\
\hline 9,000 & $2.936979 \%$ & $3.061780 \%$ & $4.085501 \%$ \\
\hline 9,500 & $2.358671 \%$ & $2.470928 \%$ & $3.390895 \%$ \\
\hline 10,000 & $1.812896 \%$ & $1.913830 \%$ & $2.740619 \%$ \\
\hline 10,500 & $1.722882 \%$ & $1.813756 \%$ & $2.556851 \%$ \\
\hline 11,000 & $1.641115 \%$ & $1.722910 \%$ & $2.390840 \%$ \\
\hline 11,500 & $1.566952 \%$ & $1.641357 \%$ & $2.248004 \%$ \\
\hline 12,000 & $1.499135 \%$ & $1.567039 \%$ & $2.119897 \%$ \\
\hline
\end{tabular}

Table 9 Sensitivity of life internal rates of return on premium of endowment plan for female.

\begin{tabular}{|c|c|c|c|}
\hline Aged & 20 & 40 & 60 \\
\hline 7,500 & $4.821615 \%$ & $4.896016 \%$ & $5.660931 \%$ \\
\hline 8,000 & $4.126773 \%$ & $4.193502 \%$ & $4.877251 \%$ \\
\hline 8,500 & $3.478144 \%$ & $3.538074 \%$ & $4.150032 \%$ \\
\hline 9,000 & $2.870053 \%$ & $2.923915 \%$ & $3.471867 \%$ \\
\hline 9,500 & $2.297807 \%$ & $2.346214 \%$ & $2.836702 \%$ \\
\hline 10,000 & $1.757476 \%$ & $1.800951 \%$ & $2.239525 \%$ \\
\hline 10,500 & $1.672505 \%$ & $1.711624 \%$ & $2.105286 \%$ \\
\hline 11,000 & $1.595291 \%$ & $1.630474 \%$ & $1.983652 \%$ \\
\hline 11,500 & $1.524957 \%$ & $1.556942 \%$ & $1.877485 \%$ \\
\hline 12,000 & $1.460544 \%$ & $1.489717 \%$ & $1.781673 \%$ \\
\hline
\end{tabular}

Next, we consider the change of constant dividend throughout the contract of male and female. The 
results of the sensitivity analysis on the dividend for male and female are shown in Table 10, and Table 11 , respectively.

Table 10 Sensitivity of life internal rates of return on dividend of endowment plan for male.

\begin{tabular}{|c|c|c|c|}
\hline Aged & 20 & 40 & 60 \\
Dividend & & & \\
\hline 100 & $1.848201 \%$ & $1.960258 \%$ & $2.878542 \%$ \\
\hline 200 & $1.990296 \%$ & $2.103328 \%$ & $3.029613 \%$ \\
\hline 300 & $2.132974 \%$ & $2.246997 \%$ & $3.181401 \%$ \\
\hline 400 & $2.276243 \%$ & $2.391270 \%$ & $3.333915 \%$ \\
\hline 500 & $2.420107 \%$ & $2.536155 \%$ & $3.487162 \%$ \\
\hline 600 & $2.564574 \%$ & $2.681658 \%$ & $3.641150 \%$ \\
\hline 700 & $2.709650 \%$ & $2.827786 \%$ & $3.795888 \%$ \\
\hline 800 & $2.855343 \%$ & $2.974545 \%$ & $3.951383 \%$ \\
\hline 900 & $3.001658 \%$ & $3.121944 \%$ & $4.107643 \%$ \\
\hline 1,000 & $3.148603 \%$ & $3.269988 \%$ & $4.264677 \%$ \\
\hline
\end{tabular}

Table 11 Table 10 Sensitivity of life internal rates of return on dividend of endowment plan for female.

\begin{tabular}{|c|c|c|c|}
\hline $\begin{array}{r}\text { Aged } \\
\text { Dividend }\end{array}$ & 20 & 40 & 60 \\
\hline 100 & $1.788031 \%$ & $1.836419 \%$ & $2.328261 \%$ \\
\hline 200 & $1.929551 \%$ & $1.978352 \%$ & $2.474268 \%$ \\
\hline 300 & $2.071646 \%$ & $2.120866 \%$ & $2.620892 \%$ \\
\hline 400 & $2.214322 \%$ & $2.263968 \%$ & $2.768170 \%$ \\
\hline 500 & $2.357586 \%$ & $2.407665 \%$ & $2.916109 \%$ \\
\hline 600 & $2.501445 \%$ & $2.551962 \%$ & $3.064716 \%$ \\
\hline 700 & $2.645904 \%$ & $2.696867 \%$ & $3.213999 \%$ \\
\hline 800 & $2.790971 \%$ & $2.842387 \%$ & $3.363965 \%$ \\
\hline 900 & $2.936652 \%$ & $2.988527 \%$ & $3.514621 \%$ \\
\hline 1,000 & $3.082954 \%$ & $3.135296 \%$ & $3.665974 \%$ \\
\hline
\end{tabular}

The sensitivity analysis for endowment plan shows that the life internal rates of return are sensitive to the change in the annual premium and dividend. It can be seen that when the premiums increase, the life internal rates of return will decrease. While, if the annual dividends increase, then the life internal rates of return also increase. These sensitivity analysis perform the same results in each different age category.

\subsection{Whole life insurance}

The sensitivity analysis of internal rates of return on premium of the whole life plan for both male and female is shown in Table 12.

The sensitivity analysis in Table 12 shows that the internal rate of return is significantly sensitive to the change in the annual premium. It can be seen that when premiums increase, the life internal rates of return decrease.

Table 12 Sensitivity of life internal rates of return on premium of whole life plan.

\begin{tabular}{|c|c|c|}
\hline $\begin{array}{c}\text { Aged } \\
\text { Premium }\end{array}$ & Male & Female \\
\hline 2,000 & $3.880308 \%$ & $3.347340 \%$ \\
\hline 2,500 & $3.059717 \%$ & $2.650793 \%$ \\
\hline 3,000 & $2.427941 \%$ & $2.104658 \%$ \\
\hline 3,500 & $1.916309 \%$ & $1.656671 \%$ \\
\hline 4,000 & $1.487516 \%$ & $1.277592 \%$ \\
\hline 4,500 & $1.119132 \%$ & $0.949460 \%$ \\
\hline 5,000 & $0.796660 \%$ & $0.660472 \%$ \\
\hline 5,500 & $0.715720 \%$ & $0.593527 \%$ \\
\hline 6,000 & $0.649252 \%$ & $0.537878 \%$ \\
\hline 6,500 & $0.593595 \%$ & $0.490839 \%$ \\
\hline
\end{tabular}

\subsection{Retirement insurance}

The sensitivity analysis for the retirement insurance, we perform the analysis in two cases, lump sum payment and installments up to age of 80 . The sensitivity analysis of the life internal rates of return on premium in both cases are represented in Table 13 and Table 14, respectively.

Table 13 Sensitivity of life internal rates of return on premium of retirement plan for lump sum option.

\begin{tabular}{|c|c|c|}
\hline $\begin{array}{r}\text { Aged } \\
\text { Premium }\end{array}$ & Male & Female \\
\hline 2,000 & $5.175790 \%$ & $4.783023 \%$ \\
\hline 2,500 & $3.633692 \%$ & $3.335189 \%$ \\
\hline 3,000 & $2.375688 \%$ & $2.139221 \%$ \\
\hline 3,500 & $1.542650 \%$ & $1.360898 \%$ \\
\hline 4,000 & $1.300317 \%$ & $1.171240 \%$ \\
\hline 4,500 & $1.123763 \%$ & $1.028753 \%$ \\
\hline 5,000 & $0.988756 \%$ & $0.917158 \%$ \\
\hline 5,500 & $0.822180 \%$ & $0.827284 \%$ \\
\hline 6,000 & $0.795637 \%$ & $0.753194 \%$ \\
\hline 6,500 & $0.723875 \%$ & $0.691010 \%$ \\
\hline
\end{tabular}

The sensitivity analysis of life internal rates of return in Table 13 and Table 14 show that the life internal rates of return are sensitive to the change of the annual premiums. It can be seen that when premiums increase, the life internal rates of return increase in both cases of payment option.

In conclusion, the sensitivity analyses demonstrate that our proposed model has the sensitivity on premium and dividend which are the factors that are subjects to change. The results show 
that life internal rates of return reflect the natural characteristics of life insurance. When the premiums increase, it is implied that the actuarial present value of money paid out in the cash flow increases, while the money received in is the same. This obviously expresses the decreases in the life internal rates of return. In contrary, when the dividends increase, it is implied that the actuarial present value of money received in increases, while the money paid out in the cash flow is the same. In this case, the life internal rates of return increase significantly.

Table 14 Sensitivity of life internal rates of return on premium of retirement plan for installments option.

\begin{tabular}{|c|c|c|}
\hline $\begin{array}{r}\text { Aged } \\
\text { Premium }\end{array}$ & Male & Female \\
\hline 2,000 & $5.312761 \%$ & $5.249980 \%$ \\
\hline 2,500 & $4.133733 \%$ & $4.183601 \%$ \\
\hline 3,000 & $3.209150 \%$ & $3.335599 \%$ \\
\hline 3,500 & $2.451053 \%$ & $2.632802 \%$ \\
\hline 4,000 & $1.819841 \%$ & $2.037740 \%$ \\
\hline 4,500 & $1.280471 \%$ & $1.521944 \%$ \\
\hline 5,000 & $0.808686 \%$ & $1.066187 \%$ \\
\hline 5,500 & $0.389125 \%$ & $0.657752 \%$ \\
\hline 6,000 & $0.010931 \%$ & $0.287531 \%$ \\
\hline 6,500 & $-0.333545 \%$ & $-0.051117 \%$ \\
\hline
\end{tabular}

\section{Conclusion}

The goal of this research was to propose the new mathematical model for the decision making on investment of life insurance products as well as to mathematically illustrate the idea of the extended model to construct a general form of internal rate of return, taking into account the life probabilities with the other necessary factors such as dividends, lapse rates, and cash surrender values, named as "Life Internal Rate of Return (Life-IRR)". Numerical calculations using the proposed model was carried out under three environments of life insurance investments; endowment, whole life, and retirement plans. The proposed tool for investment decision making provides the outcomes of making these investments depending on the random premium, dividend, surrender value, annuity certain and lapse rate, fixed sum assured and death benefit.

Moreover, all of the sensitivity analyses demonstrate that our proposed investment tool can reflect the nature of life insurance obviously, which implies that the life internal rate of return can apply to life insurance. In the real world of life uncertainty, it is hard to compare the investment in life insurance products by expecting the certain outcomes, since each life insurance product may be composed of elements of life contingencies. Thus, the main advantage of our proposed model is to provide a mathematical tool for decision making in the life insurance investment which depends on life contingencies.

In conclusion, based on the sample data for a 30year-old male and female investors, it is suggested that investors of both genders aged 30 should invest in a retirement plan that receives maturity benefit as a lump sum that has the highest life internal rate of return. On the other hand, the least yielding life insurance is the whole life plan for female and the endowment plan for male. However, it is noted that these are the results of the specified cases of the given situation. In different situations, the results may not be the same.

\section{References:}

[1] Office of insurance commission. (2016, November). Growth \& Credibility 2016-2020 (3rd ed.) [Magazine]. Available: http://www.oic.or.th/sites/default/files/file_dow nload/ediiyw_final_khpph_-

hnangsuueaephnphathnaakaarprakanphay_chb abthii_3_resize_1.pdf

[2] Office of insurance commission. Networks (1st ed.) [Online]. Available: https://www.oic.or.th/en/node/89363?fbclid=Iw AR013BT5AsfQBhzVst9Fj8n0MEJdBIYUHg $\mathrm{F} \backslash \backslash \mathrm{NrC} 5 \mathrm{LhDx} 12 \ln b \mathrm{~W} 7 \mathrm{ax} 5 \mathrm{NwcJGs}$

[3] M.A. Mian, Project Economics and Decision Analysis: Deterministic models. Tulsa, Oklahoma USA, 2002, pp. 64.

[4] O. Jan, (2020, May 18). Networks (2nd ed.) [Online]. Available: https://xplaind.com/362789/npv-vs-irr

[5] I. V. Pareja, "Ranking and optimal selection of investments with internal rate of return and benefit-cost ratio: a revision," Contaduríay Administración, vol. 57, no. 1, 2011, pp. 29-51.

[6] R. Turvey, "Present value versus internal rate of return-an essay in the theory of the third best," Economic Journal, vol. 73, no. 289, 1963, pp. 93-98.

[7] C. A. Magni, "Average internal rate of return and investment decisions: a new perspective," The Engineering Economist, vol. 55, no. 2, 2010, pp. 150-180.

[8] L. Juhász, "Net present value versus internal rate of return," Economics \& Sociology, vol. 4, no 1, 2011, pp. 46-53.

[9] L. Romele, "Estimation of internal rate of return (IRR) to investments in education in Latvia," 
International Journal of Social Science and Humanity, vol. 3, no. 1, 2013, pp. 1-4.

[10] T. R. Vaughn, "Misapplications of internal rate of return models in property/liability insurance ratemaking," in Proc. Casualty Actuarial Society, Maryland, 2002, pp. 399-416.

[11] X. Duan, Systematic Risk Measurement Based on CoVaR Model, International Journal of Circuits, Systems and Signal Processing, vol. 13, 2019, pp. 243-250.

[12] S. Feldblum, "Pricing Insurance Policies: The Internal Rate of Return Model," CAS Study Note, 1992, ch. 2.

[13] R. Stevens, A. D. Waegenaere, and B. Melenberg, "Longevity Risk and Hedge Effects in a Portfolio of Life Insurance Products with Investment Risk," Tilburg CentER Discussion Paper Series, no. 2011-036, 2011, pp. 1-46.

[14] F. Dong, N. Halen, K. Moore, and Q. Zeng, "Efficient Retirement Portfolios: Using Life Insurance to Meet Income and Bequest Goals in Retirement," MDPI, vol. 7, no. 9, 2019, pp.111.

[15] P. R. Kensicki, "Consumer Valuation of Life Insurance- A Capital Budgeting Approach," The Journal of Risk and Insurance, vol. 41, no. 4, 1974, pp. 655-665.

[16] J. M. Belth, "Distribution of Surplus to Individual Life Insurance Policy Owners," JSTOR, vol. 45, no. 1, 1978, pp. 7-26.

[17] M. L. Smith, "The Life Insurance Policy as an Options Package," JSTOR, vol. 49, no. 4, 1982, pp. 583-601.

[18] X. Milhaud, and C. Dutang, "Lapse tables for lapse risk management in insurance: a competing risk approach," European Actuarial Journal, vol. 8, 2018, pp. 97-126.

[19] M. Dash, "The Internal Rate of Return Model for Life Insurance Policies," Asian Journal of Finance \& Accounting, vol. 8, no. 2, 2016, pp. $70-94$.

[20] Office of insurance commission (2017). The Thai mortality table 2017. [Data] Available: http://www.oic.or.th/en/consumer/87479.

\section{Acknowledgment}

The authors would like to greatly thank the Centre of Excellence in Mathematics, CHE, Thailand, for all supports under Contract RG-01-63-01-1.

\section{Appendix}

The life probabilities applied to this research is from Thai mortality table (ages 1-99) for the year 2017 [20], Table 15.
Table 15 The Thai mortality table 2017

\begin{tabular}{|c|c|c|c|c|c|}
\hline $\begin{array}{c}\text { Age } \\
(k)\end{array}$ & Male & Female & $\begin{array}{c}\text { Age } \\
(k)\end{array}$ & Male & Female \\
\hline 0 & 0.0013 & 0.0011 & 50 & 0.0050 & 0.0021 \\
\hline 1 & 0.0003 & 0.0002 & 51 & 0.0054 & 0.0022 \\
\hline 2 & 0.0003 & 0.0002 & 52 & 0.0058 & 0.0025 \\
\hline 3 & 0.0003 & 0.0002 & 53 & 0.0063 & 0.0027 \\
\hline 4 & 0.0002 & 0.0002 & 54 & 0.0067 & 0.0030 \\
\hline 5 & 0.0002 & 0.0002 & 55 & 0.0073 & 0.0033 \\
\hline 6 & 0.0002 & 0.0002 & 56 & 0.0079 & 0.0037 \\
\hline 7 & 0.0002 & 0.0002 & 57 & 0.0085 & 0.0041 \\
\hline 8 & 0.0002 & 0.0002 & 58 & 0.0093 & 0.0045 \\
\hline 9 & 0.0002 & 0.0002 & 59 & 0.0102 & 0.0050 \\
\hline 10 & 0.0002 & 0.0002 & 60 & 0.0111 & 0.0056 \\
\hline 11 & 0.0003 & 0.0002 & 61 & 0.0122 & 0.0062 \\
\hline 12 & 0.0004 & 0.0002 & 62 & 0.0135 & 0.0070 \\
\hline 13 & 0.0005 & 0.0003 & 63 & 0.0149 & 0.0078 \\
\hline 14 & 0.0006 & 0.0003 & 64 & 0.0165 & 0.0088 \\
\hline 15 & 0.0008 & 0.0003 & 65 & 0.0183 & 0.0100 \\
\hline 16 & 0.0009 & 0.0003 & 66 & 0.0203 & 0.0114 \\
\hline 17 & 0.0010 & 0.0003 & 67 & 0.0226 & 0.0130 \\
\hline 18 & 0.0011 & 0.0021 & 68 & 0.0252 & 0.0149 \\
\hline 19 & 0.0012 & 0.0022 & 69 & 0.0281 & 0.0172 \\
\hline 20 & 0.0013 & 0.0025 & 70 & 0.0314 & 0.0198 \\
\hline 21 & 0.0013 & 0.0003 & 71 & 0.0352 & 0.0228 \\
\hline 22 & 0.0014 & 0.0004 & 72 & 0.0394 & 0.0262 \\
\hline 23 & 0.0014 & 0.0004 & 73 & 0.0441 & 0.0300 \\
\hline 24 & 0.0014 & 0.0004 & 74 & 0.0492 & 0.0343 \\
\hline 25 & 0.0014 & 0.0004 & 75 & 0.0549 & 0.0390 \\
\hline 26 & 0.0015 & 0.0004 & 76 & 0.0611 & 0.0440 \\
\hline 27 & 0.0015 & 0.0004 & 77 & 0.0677 & 0.0495 \\
\hline 28 & 0.0015 & 0.0004 & 78 & 0.0747 & 0.0554 \\
\hline 29 & 0.0015 & 0.0005 & 79 & 0.0821 & 0.0617 \\
\hline 30 & 0.0016 & 0.0005 & 80 & 0.0899 & 0.0685 \\
\hline 31 & 0.0017 & 0.0005 & 81 & 0.0980 & 0.0757 \\
\hline 32 & 0.0018 & 0.0005 & 82 & 0.1065 & 0.0835 \\
\hline 33 & 0.0018 & 0.0005 & 83 & 0.1154 & 0.0919 \\
\hline 34 & 0.0013 & 0.0011 & 84 & 0.1247 & 0.1009 \\
\hline 35 & 0.0003 & 0.0002 & 85 & 0.1345 & 0.1106 \\
\hline 36 & 0.0003 & 0.0002 & 86 & 0.1449 & 0.1212 \\
\hline 37 & 0.0003 & 0.0002 & 87 & 0.1559 & 0.1327 \\
\hline 38 & 0.0002 & 0.0002 & 88 & 0.1704 & 0.1468 \\
\hline 39 & 0.0002 & 0.0002 & 89 & 0.1862 & 0.1625 \\
\hline 40 & 0.0002 & 0.0002 & 90 & 0.2034 & 0.1799 \\
\hline 41 & 0.0002 & 0.0002 & 91 & 0.2223 & 0.1991 \\
\hline 42 & 0.0002 & 0.0002 & 92 & 0.2429 & 0.2204 \\
\hline 43 & 0.0002 & 0.0002 & 93 & 0.2655 & 0.2439 \\
\hline 44 & 0.0002 & 0.0002 & 94 & 0.2878 & 0.2679 \\
\hline 45 & 0.0003 & 0.0002 & 95 & 0.3115 & 0.2937 \\
\hline 46 & 0.0004 & 0.0002 & 96 & 0.3368 & 0.3215 \\
\hline 47 & 0.0005 & 0.0003 & 97 & 0.3635 & 0.3511 \\
\hline 48 & 0.0006 & 0.0003 & 98 & 0.3916 & 0.3827 \\
\hline 49 & 0.0008 & 0.0003 & 99 & 1.0000 & 1.0000 \\
\hline & & & & & \\
\hline
\end{tabular}


Contribution of individual authors to the creation of a scientific article (ghostwriting policy)

Both authors contributed equally to this work.

Sources of funding for research presented in a scientific article or scientific article itself

This work was financially supported by the Centre of Excellence in Mathematics, CHE, Thailand, under Contract RG-01-63-01-1.

\section{Creative Commons Attribution}

\section{License $\quad 4.0 \quad$ (Attribution $\quad \mathbf{4 . 0}$}

International , CC BY 4.0)

This article is published under the terms of the Creative Commons Attribution License 4.0

https://creativecommons.org/licenses/by/4.0/deed.en US 